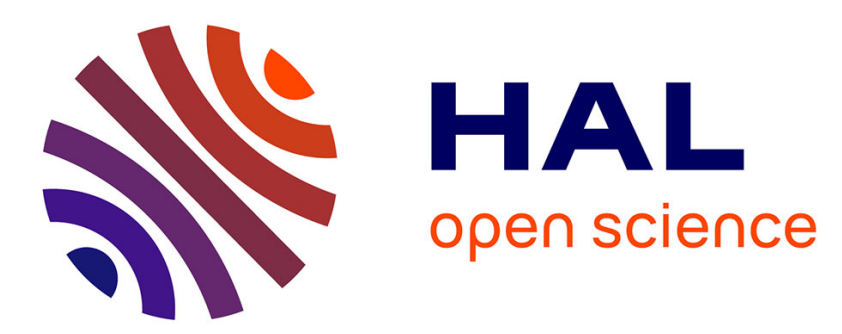

\title{
The DEMETER mission, recent investigations on ionospheric effects associated with man-made activities and seismic phenomena
}

Tatsuo Onishi, Michel Parrot, Jean-Jacques Berthelier

\section{- To cite this version:}

Tatsuo Onishi, Michel Parrot, Jean-Jacques Berthelier. The DEMETER mission, recent investigations on ionospheric effects associated with man-made activities and seismic phenomena. Comptes Rendus. Physique, 2011, 12 (2), pp.160-170. 10.1016/j.crhy.2010.11.009 . hal-00585196

\section{HAL Id: hal-00585196 https://hal.science/hal-00585196}

Submitted on 9 Mar 2015

HAL is a multi-disciplinary open access archive for the deposit and dissemination of scientific research documents, whether they are published or not. The documents may come from teaching and research institutions in France or abroad, or from public or private research centers.
L'archive ouverte pluridisciplinaire HAL, est destinée au dépôt et à la diffusion de documents scientifiques de niveau recherche, publiés ou non, émanant des établissements d'enseignement et de recherche français ou étrangers, des laboratoires publics ou privés. 


\title{
The DEMETER mission, recent investigations on ionospheric effects associated with man-made activities and seismic phenomena
}

\section{La mission DEMETER, investigations récentes sur d'effets ionosphériques associés à l'activité de l'homme, et à l'activité sismique}

\author{
Tatsuo Onishi ${ }^{\mathrm{a}, *}$, Michel Parrot ${ }^{\mathrm{b}}$, Jean-Jacques Berthelier ${ }^{\mathrm{a}}$ \\ a LATMOS/IPSL, CNRS-UVSQ-UPMC, 11, boulevard d'Alembert, 78280 Guyancourt cedex, France \\ ${ }^{\mathrm{b}}$ LPC2E, 3, avenue de la recherche scientifique, 45045 Orléans cedex, France
}

\section{A R T I C L E I N F O}

\section{Keywords:}

Ionosphere

Seismic activity

Natural and man-made electromagnetic emissions

\section{Mots-clés:}

Ionosphère

Activité sismique

Onde naturelle et émissions artificielles

\begin{abstract}
A B S T R A C T
Two of the main scientific objectives of the DEMETER mission concerned the search for ionospheric effects due to earthquakes and the study of disturbances associated with human activities or natural phenomena such as thunderstorms. The large data base gathered during nearly 6 years of in-orbit operation has lead to making new observations and/or to improving the understanding of several, already identified, phenomena. The main effects of human activities are observed in the field of radio-electric emissions and we present several results on the EM waves generated by power networks or associated with high power VLF transmitters. The search for ionospheric disturbances associated with earthquakes relies on thorough statistical studies to disentangle seismic effects from the variations induced by the physical processes that control the ionospheric plasma and natural emissions. Several studies are presented, and one of them has demonstrated a decrease of the ELF wave intensity in the frequency range between 1 and $2 \mathrm{kHz}$ a few hours before the shock.
\end{abstract}

(c) 2010 Académie des sciences. Published by Elsevier Masson SAS. All rights reserved.

\section{R É S U M É}

Deux des principaux objectifs scientifiques de la mission DEMETER, concernaient la recherche d'effets ionosphériques associés à l'activité sismique et l'étude des perturbations engendrées par l'activité humaine ou les phénomènes naturels tels les orages. Les données acquises depuis presque 6 ans en orbite ont fourni matière à des observations inédites et/ou à des progrès substantiels dans la compréhension de phénomènes déjà connus. Après une brève description de la charge utile et des modes de fonctionnement, nous donnons un aperçu de quelques résultats récents des travaux entrepris dans ces deux domaines. Les effets de l'activité humaine intéressent essentiellement les émissions radioélectriques et nous présentons plusieurs résultats concernant les émissions engendrées par les réseaux électriques et les perturbations de l'ionosphère par les émetteurs VLF de forte puissance. En ce qui concerne les perturbations d'origine sismique, nous présentons les études statistiques réalisées pour caractériser les ondes naturelles et permettre de distinguer d'éventuels effets sismiques. L'une d'entre elles a permis de mettre en évidence

\footnotetext{
* Corresponding author.

E-mail address: tatsuo.onishi@latmos.ipsl.fr (T. Onishi).
} 
une diminution de l'intensité des ondes naturelles dans le domaine ELF, entre 1 et $2 \mathrm{kHz}$, quelques heures avant les séismes.

(C) 2010 Académie des sciences. Published by Elsevier Masson SAS. All rights reserved.

\section{Introduction}

The DEMETER micro-satellite mission was proposed by a group of scientists involved in external and internal geophysics. One of its main scientific objectives is to detect anomalous variations of electromagnetic waves, particle fluxes or thermal plasma parameters which could be related to seismic activity. This is an old problem [1] but, in the recent years, the possible existence of ionospheric precursors of strong earthquakes has attracted much attention in the space physics community. There are presently many uncertainties and controversies about the actual origin of many observed ionospheric effects that may possibly be related with pre-earthquake seismic activity. Indeed, numerous processes of solar or magnetospheric origin may trigger plasma and wave disturbances in the ionosphere that can be erroneously attributed to the effect of seismic activity. However the detection and understanding of real and systematic ionospheric disturbances prior to earthquakes is an important question not only to unravel the physical processes at work but also because they could be considered as short-term precursors, occurring between a few hours and a few days before earthquakes. A number of ideas have been proposed to explain a lithosphere-atmosphere-ionosphere coupling and to account for effects in the ionosphere. Examples may be found in [2-4] and references therein.

The second scientific objective of DEMETER is to study the effect of anthropogenic activities (Power Line Harmonic Radiation, VLF transmitters, HF broadcasting stations) on the ionosphere. Last but not least, the nearly continuous survey of plasma and waves provided by DEMETER over a period of more than 6 years has offered unique opportunities to perform detailed space weather studies, in particular during a few intense magnetic storms, and to study the long term evolution of the ionosphere during the prolonged period of extremely low solar activity in the second half of the last solar cycle.

The aim of this paper is to present some results related to the main objectives of the mission. In Section 2 we briefly describe the scientific payload and the plasma and waves data routinely processed by the DEMETER Mission Centre. Examples of the effects of man-made activities and of disturbances observed above seismic regions will be shown in Sections 3 and 4, respectively. Conclusions will be presented in Section 5.

\section{The DEMETER scientific payload and modes of operation}

DEMETER, with overall dimensions $80 \times 60 \times 60 \mathrm{~cm}$ and a total mass of $130 \mathrm{~kg}$ including a scientific and technical payload of $50 \mathrm{~kg}$, is the first micro-satellite developed by CNES (French National Space Agency) in the frame of the Myriade microsatellite program [5]. Launched on June 29, 2004 from Baïkonour (Kazakhstan) by a Dnepr rocket, DEMETER was placed on a nearly circular ( $\sim 715 \mathrm{~km}$ altitude) and polar $\left(98^{\circ}\right.$ inclination) quasi-helio-synchronous orbit with ascending and descending nodes respectively at $\sim 22.30$ LT and 10.30 LT. In September 2006 the orbit was lowered to $\sim 670 \mathrm{~km}$ altitude inducing a slightly larger drift in local time. DEMETER is 3 axis stabilized with one axis pointing towards nadir and another one directed along the orbital velocity. At the time of preparation of this paper (May 2010) the satellite and the instruments are still performing nominally but it is planned to end the satellite operation phase by the end of December 2010 .

The scientific payload is fairly complete, including 2 plasma wave experiments ICE and IMSC, 2 thermal plasma experiments, ISL and IAP and an energetic particle detector IDP.

ICE [6] consists of 4 spherical probes and the associated BANT signal processing electronics to measure the 3 components of electric fields from DC to $3.25 \mathrm{MHz}$ using the double probe technique. There are 4 frequency ranges, DC-ULF from 0 to $15 \mathrm{~Hz}$, ELF from $15 \mathrm{~Hz}$ to $1 \mathrm{kHz}$, VLF from $10 \mathrm{~Hz}$ to $17 \mathrm{kHz}$ and $\mathrm{HF}$ from $10 \mathrm{kHz}$ to $3.25 \mathrm{MHz}$. IMSC [7] uses an assembly of 3 orthogonal search-coil magnetic antennas and the BANT electronics to measure the 3 components of AC electric fields at ELF and VLF from $10 \mathrm{~Hz}$ to $17 \mathrm{kHz}$. ISL [8] uses a cylindrical Langmuir probe to determine the electron density and temperature. IAP [9] combines a retarding potential analyzer and a velocity direction analyzer to measure the ion density, composition and temperature and the ion bulk velocity. IDP [10] measures the energetic electrons from $70 \mathrm{keV}$ to $1 \mathrm{MeV}$, providing also information at energies up to $2.5 \mathrm{MeV}$.

The scientific payload is operated nearly continuously at geographic latitudes below $65^{\circ}$ since most of the seismically active regions are located at low to mid latitudes. Some passes have been programmed up to $\sim 75^{\circ}$ latitude in conjunction with ground-based experiments of special interest such as the EISCAT ISR's or the HAARP high power transmitter. There are two modes of operation, a Survey mode that aims at providing a continuous coverage of plasma, waves and energetic electron measurements at latitudes less than $65^{\circ}$, and a Burst mode which is activated for shorter periods of time when the satellite flies over seismic regions and provides data with a higher time resolution. All raw data are stored in real time in a mass memory that is read 2 times a day when the satellite flies over the CNES receiving station at Toulouse (France). These raw data are processed in the DEMETER Science Mission Centre [11] and high level N1 and N2 data are made available within about 1 day after reception through the DEMETER data base.

In Survey modes, in addition to the waveforms of the 3 components of the DC-ULF electric fields, the spectra of 1 electric component in the VLF and HF ranges and of 1 magnetic component in the VLF range are obtained every $\sim 2$ s. In Burst modes, in addition to these data, the waveforms of the 3 electric components and 3 magnetic components of ELF plasma 

DEMETER
Date $_{(y / m /(0)}: 2010 / 01 / 06$
Orbit: 29507_0

ICE VLF Spectrogram E12

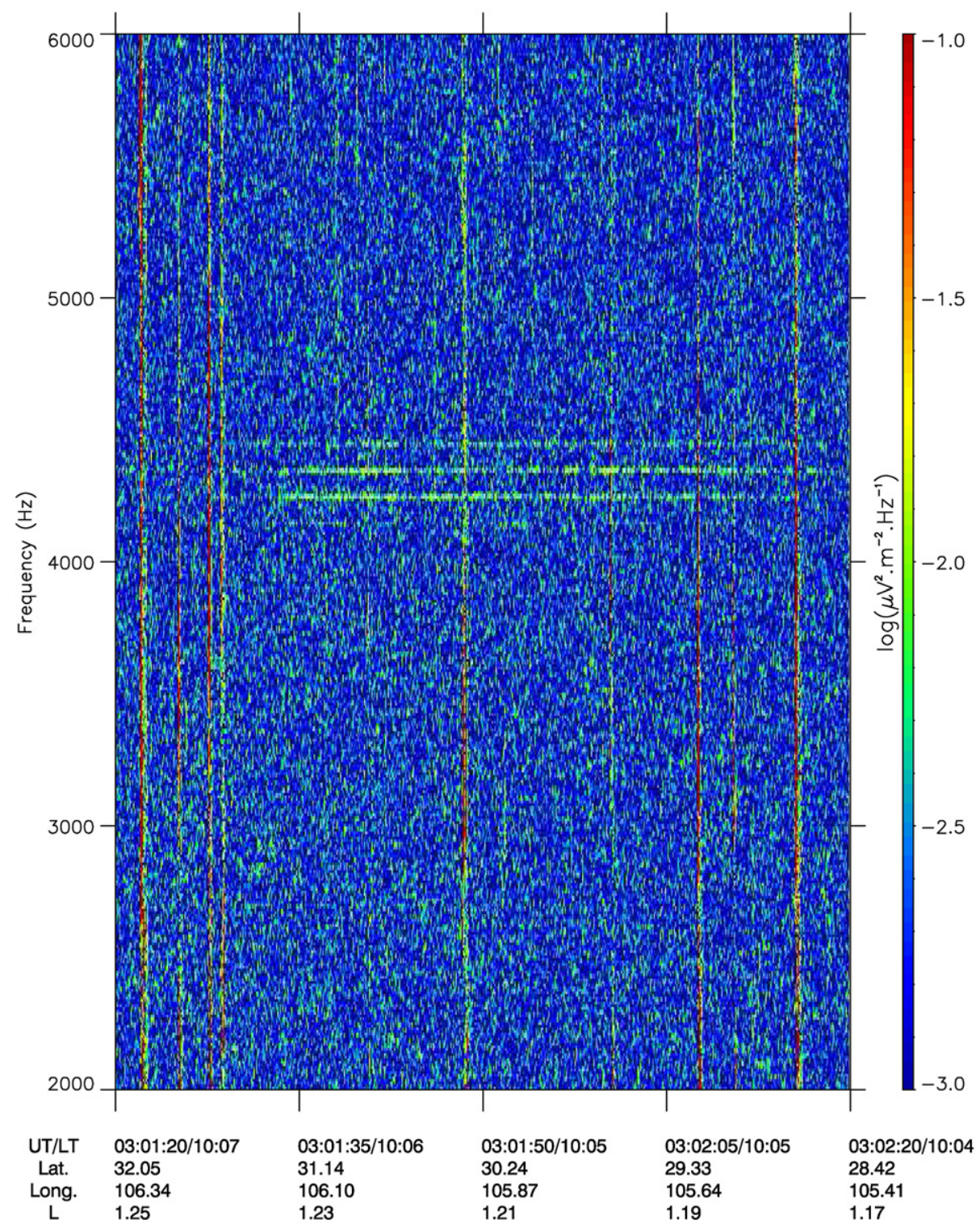

Fig. 1. Example of PLHR observed over China on January 6, 2010 between 03:01:20 and 03:02:20 UT. The spectrogram is in the frequency range 2000$6000 \mathrm{~Hz}$. The vertical lines are whistlers.

waves are available together with the VLF waveform of 1 magnetic and 1 electric components as well as short duration snapshots of the HF electric field of the same component as in VLF.

The time resolution of the plasma parameters provided by the DEMETER Mission Centre are $1 \mathrm{~s}$ for ISL (electron density and temperature) in both Survey and Burst modes, and $\sim 4 \mathrm{~s}$ for the ion parameters measured by IAP in Survey modes and $\sim 2 \mathrm{~s}$ in Burst modes.

\section{In-orbit detection of the effects of man-made activities}

The effects of man-made activities will be illustrated by presenting two typical man-made emissions which can propagate in the ionosphere: the PLHR and the VLF waves originating from high power VLF transmitters.

PLHR stands for Power Line Harmonic Radiation and these waves are believed to be caused not only by power lines but also by electromagnetic radiation from electric power systems on the ground. One example of PLHR is shown in Fig. 1 where a set of equidistant frequency lines separated by $100 \mathrm{~Hz}$ are present around $4300 \mathrm{~Hz}$. Most of the time, only high 


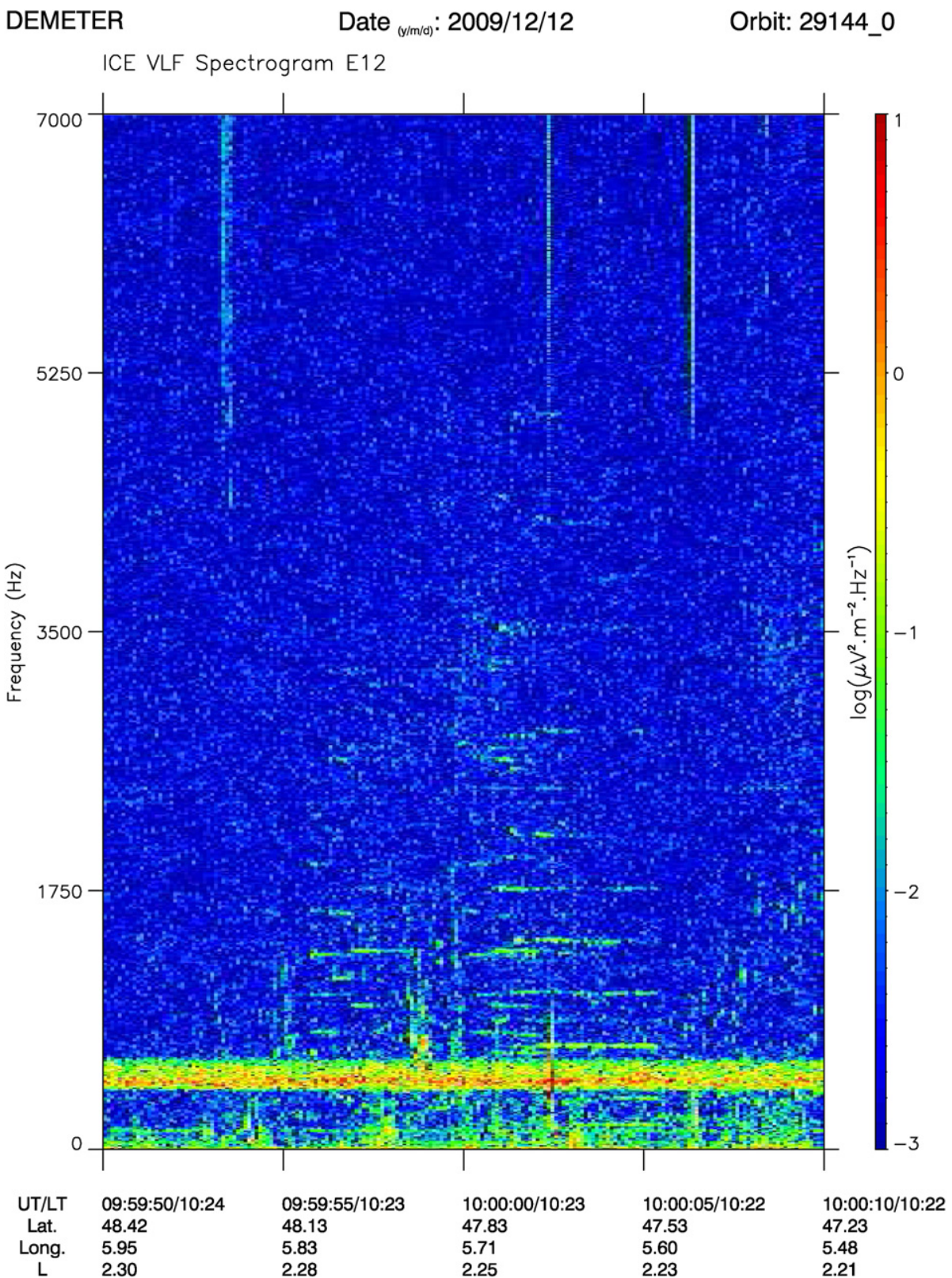

Fig. 2. Spectrogram showing industrial noise recorded when the satellite is at the conjugate point of the Ruhr area at $660 \mathrm{~km}$ altitude in the same hemisphere. The broad frequency band around $500 \mathrm{~Hz}$ is a natural noise. The vertical lines at the top of the spectrogram are whistlers.

order harmonics are observed in a frequency range between 2000 and $5000 \mathrm{~Hz}$ because these are the harmonics actually emitted from the ground [12,13]. A systematic search of these lines has been automatically done in the data when DEMETER is operating in Burst mode [14-16]. It has been shown that the frequency spacing between lines do correspond to the fundamental frequency of the power system frequency in the regions where the waves are possibly generated, $50 \mathrm{~Hz}$ above Europe and $60 \mathrm{~Hz}$ above the USA. The role of PLHR in the ionosphere is still not fully understood but it is thought that they can trigger new emissions [12,13,17] by interacting with energetic particles in the equatorial region. The more puzzling point is that other emissions are also detected with frequency lines not exactly separated by $50 / 100$ or $60 / 120 \mathrm{~Hz}$ and drifting in frequency. They are called Magnetospheric Line Radiation (MLR). They have been investigated by Němec et al. [14], who performed a systematic survey of MLR-like events using DEMETER measurements. They confirmed the existence of the two classes of events (PLHR and MLR) and demonstrated their different properties. A more complete study of the MLR properties has been done by Němec et al. [18]. One hypothesis has been proposed to explain some of the MLR events based on the non-linear gyro-resonant interaction of man-made PLHR at the magnetic equator. The intensity of the PLHR is often not strong enough to be directly observed in the ionosphere but the resulting EM waves that propagate to high altitudes are 

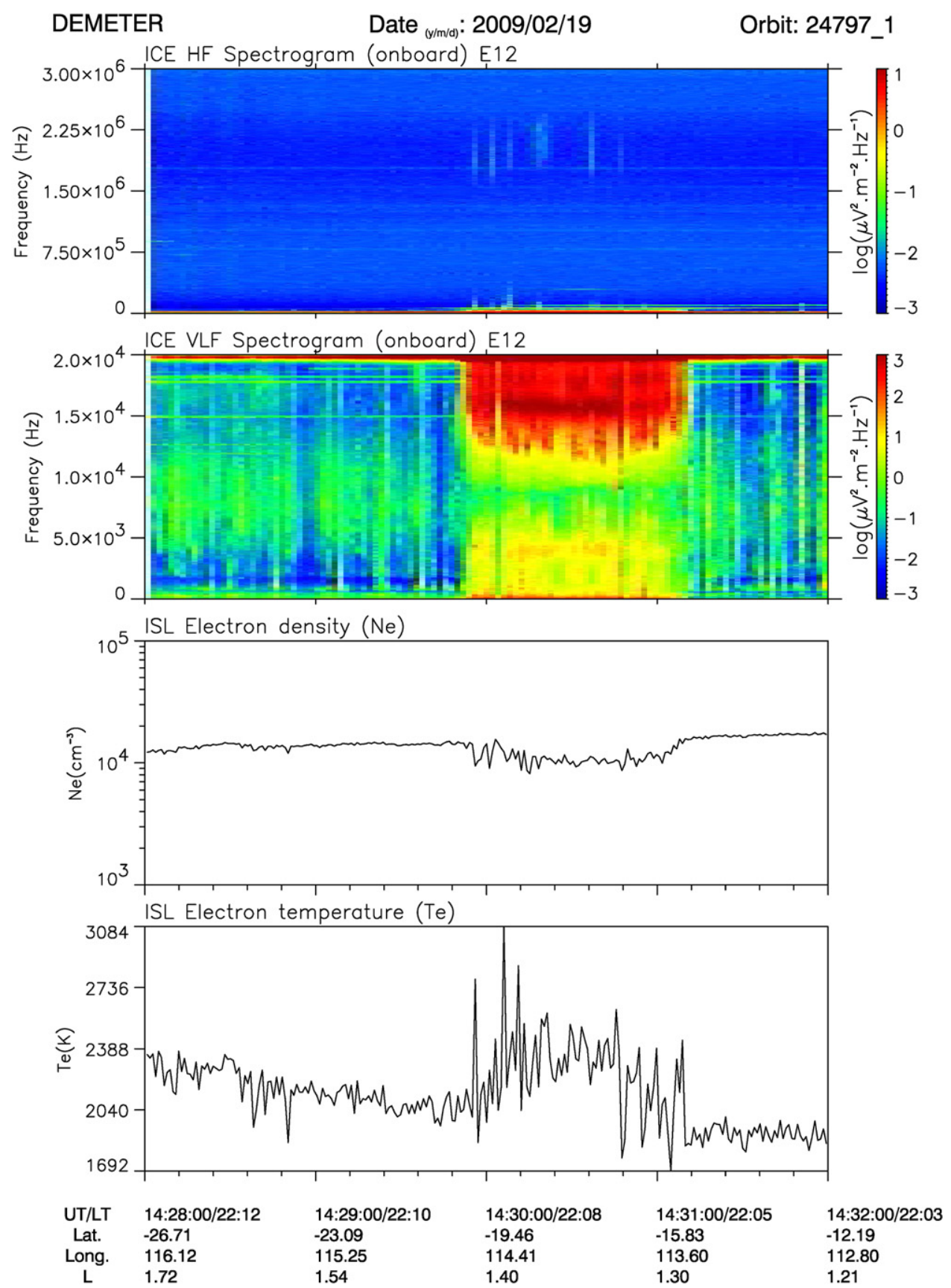

Fig. 3. Plasma and wave disturbances induced by the NWC transmitter on February 19, 2009. From top to bottom: • HF and VLF spectrograms of one component of the electric field, • electron density and temperature. The $19.8 \mathrm{kHz}$ frequency of the transmitter can be observed at the top of the VLF spectrogram.

amplified after equatorial interaction (MLR) and can then be registered. Sporadic man-made emissions can be also observed and, displayed in Fig. 2, is an example of the EM noise originating from industrial sources which is systematically registered when DEMETER is above the Ruhr area in Germany.

High power ground-based VLF transmitters are used in various countries for military communications. They transmit EM waves at fixed frequencies which propagate in the Earth-ionosphere wave guide. In presence of irregularities in the lower ionosphere these waves can cross the ionospheric boundary and be observed by a satellite. DEMETER has shown that the most powerful transmitter NWC in Australia perturbs and heats the ionosphere [19]. Fig. 3 displays a typical example of the disturbances induced in the ionospheric plasma at the orbital altitude of $660 \mathrm{~km}$ when the satellite crosses the magnetic field lines that intersect the Earth's surface close to the transmitter location. In the disturbed zone, the electron density decreases and the electron temperature increases and is subject to large fluctuations. Simultaneously, one can observe the 
presence of whistler waves in the HF part of the spectrum, close to $2 \mathrm{MHz}$, while no such HF waves are observed outside of the disturbed region even if numerous whistler waves are observed in the VLF range. Many passes close to NWC indicate that the surface of the disturbed region in the ionosphere is about $500,000 \mathrm{~km}^{2}$. These observations can be interpreted by the formation, due to the high power EM waves radiated by NWC, of a "hole" in the ionospheric plasma through which HF waves emitted by lightning and propagating in the Earth-ionosphere wave guide can escape [17]. It must be underlined that the disturbed ionosphere is not located in the region where energetic electrons are precipitated after interacting with the transmitter waves [20]. Thus the plasma irregularities are solely due to the effect of the high amplitude VLF waves on the ionosphere.

\section{Signals observed over active seismic regions}

\subsection{Plasma observations}

Quite unusual features in waves, plasma or energetic particle fluxes were recorded when the satellite was flying over epicenters of future earthquakes. Examples of ionospheric observations made by the DEMETER satellite over seismic regions have been already shown [21-23]. Fig. 4 displays an example of an ionospheric density increase when the orbit of the satellite is flying above the future epicentre of an earthquake. This earthquake with a magnitude M 5.1 occurred on February 10 , 2006 at 17:51:54 UT and the epicentre was located on the Chile coast at $32.52^{\circ} \mathrm{S}$ and $288.61^{\circ} \mathrm{E}$. The density increase is recorded a few hours before the shock.

\subsection{Wave observations}

One has to keep in mind that the plasma parameters and wave characteristics also display variations in absence of seismic activity since the mid-latitude ionosphere is affected by a number of other sources of perturbations. At mid and low latitudes, the ionosphere displays variations on a wide range of time-scales [24,25] in particular at night. This variability arises for a large part from the varying electric fields and thermospheric winds associated with auroral events. Therefore, the main objective in analyzing the DEMETER data is to perform statistical studies in order to characterize the ionospheric variations which are not related to seismic activity and be able to subtract them from the disturbances observed during seismic active periods.

\subsubsection{Statistical study of night-side natural wave emissions}

Němec et al. [26] performed a statistical study on the variations of the VLF electric field up to $10 \mathrm{kHz}$. More than 2.5 years of satellite data have been analyzed and about 9000 earthquakes with magnitudes larger than or equal to 4.8 have been taken into account. In a first step, geographic maps of the electric field intensity are built as a function of various parameters (local time, magnetic activity, frequency, and season) that are known to have a definite influence on EM waves. During the period of analysis a histogram of the wave electric field intensity and a cumulative distribution function in the range between 0 and 1 are built for each cell of these maps. In a second step, the data related to earthquakes (orbits of the satellite close to the epicentres in space and in time) are considered. The values of the recorded data along the orbits are compared with the histograms in the corresponding geographic cells to determine at which values of the cumulative distribution function they correspond. A superposed epoch method (all earthquake times are considered at origin) is then used to display these values of the cumulative distribution function considering the time (before and after the earthquakes) and the distance between the projection of the satellite orbit and the epicentres. This study has shown that, in the night sector around the 22.30 LT pass of DEMETER, there is a statistically significant decrease by $4-6$ dB of the measured wave intensity shortly ( $\sim 4$ hours) before earthquakes with their epicentre at a depth less than or equal to $40 \mathrm{~km}$. Aftershocks have been removed from the data base in order not to mix pre- and post-seismic effects. It is important to note that the frequency band where the decrease is observed can be related to the cutoff frequency of the first TM mode in the Earth-ionosphere guide (1.7 kHz during the night time). According to a recent paper by Harrison et al. [27], this effect may result from an increase of the electric conductivity in the lower troposphere due to an increase of radon emanation prior to a major earthquake. The corresponding variation of the vertical atmospheric current that flows between the ionosphere and the surface of the Earth would modify the lower D-region electron density profile and the cut-off frequency of the Earth-ionosphere waveguide.

\subsubsection{On-going studies of wave emissions}

Other sources of variability should also be taken into account when analyzing wave data because they may induce significant uncertainties when searching for a possible influence of seismic activity. The first effect to be considered is the variation in latitude and, to a lesser degree, in longitude of natural plasma waves such as the day-side plasmaspheric hiss. Since the propagation of plasmaspheric hiss is controlled by the Earth's magnetic field, the cut-off frequencies observed over equatorial seismic region (e.g. Indonesia) are lower than those over mid-latitude seismic regions (e.g. Japan). When making a detailed statistical analysis of day-side wave emissions over seismic regions one should thus be aware that the same frequency band may be above or below the cut-off frequency depending on the latitude (and to a lesser degree on longitude) of the earthquake epicentre and, consequently, the wave amplitude distribution function is widely different. In other words, 


\section{DEMETER}

Date $_{(y / m / d)}: 2006 / 02 / 10$

Orbit: 08559_1
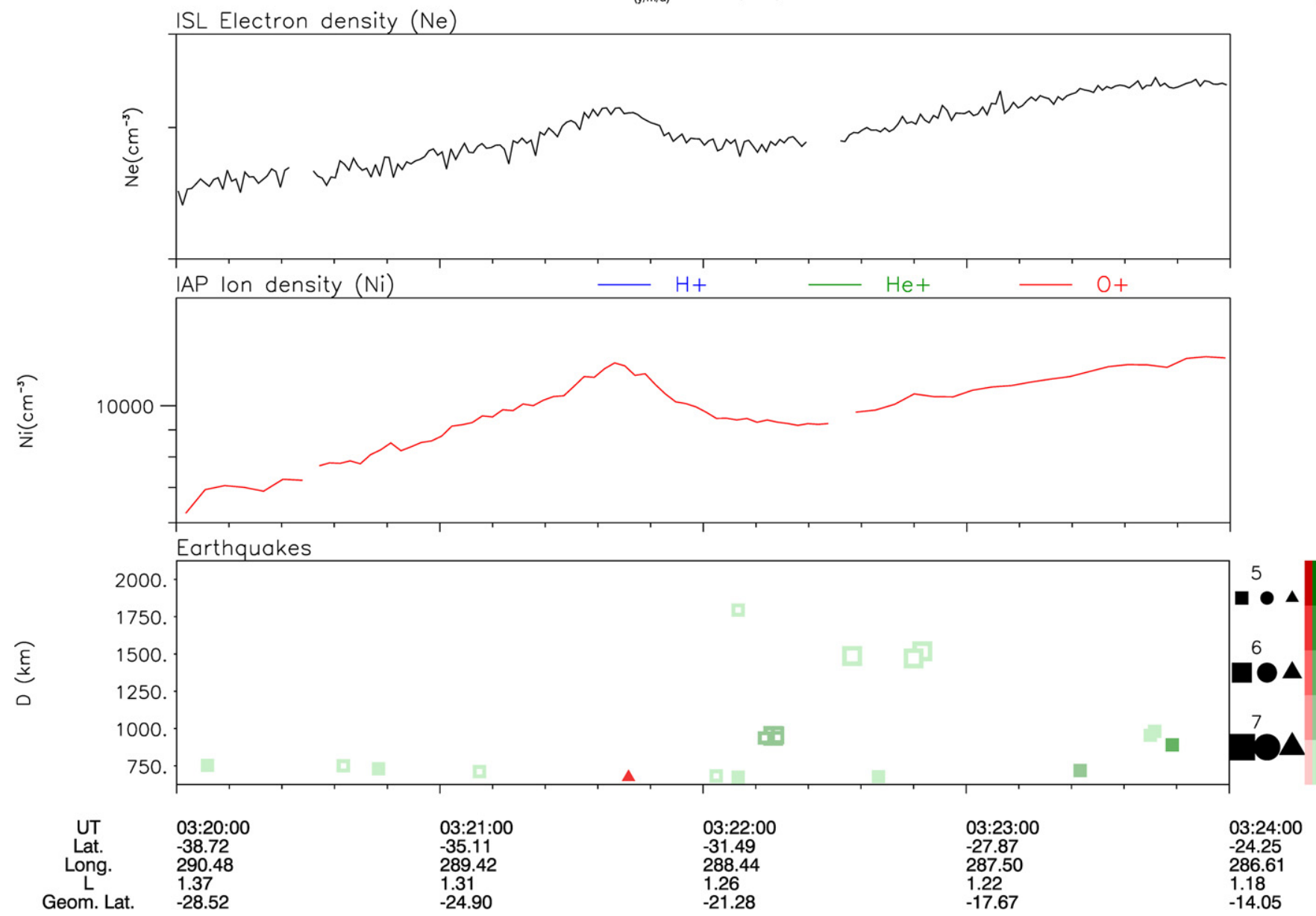

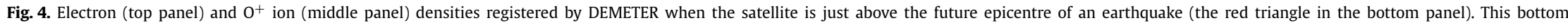

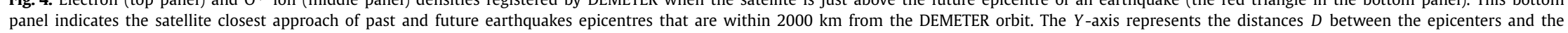

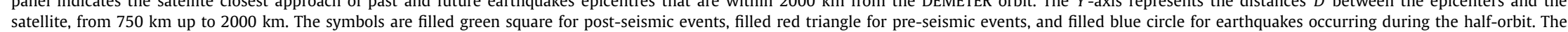

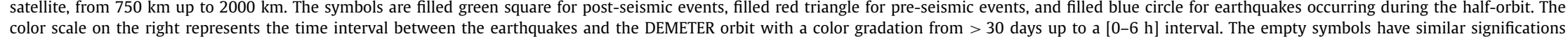

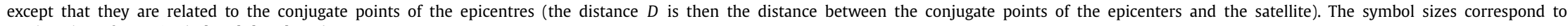
earthquakes of magnitude [5-6], [6-7], and [> 7]. 


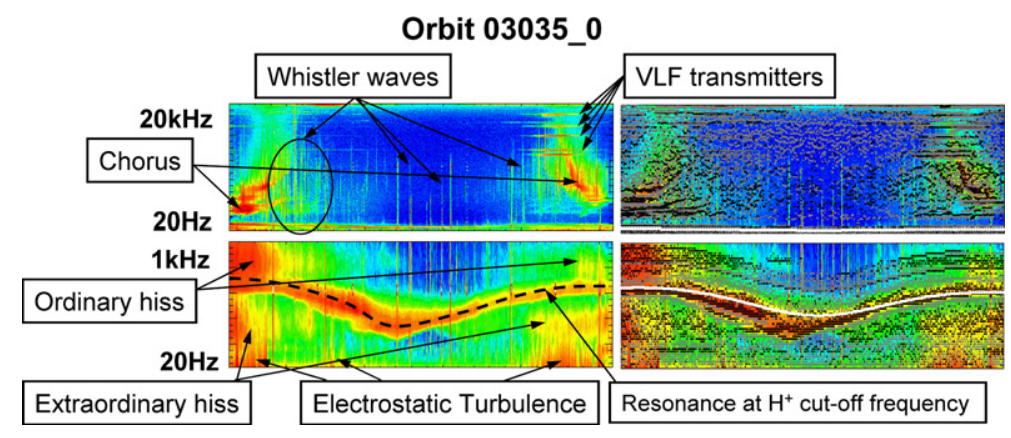

Fig. 5. $2 \mathrm{~s}$ averaged ICE VLF spectrum in VLF range (above) and ELF range (below) with indications of characteristic plasma emissions detected by the automatic recognition method (left) and overview of the information provided by the method (right). The proton gyro-frequency is plotted as a white line. Whistler waves are detected by a separate method (not shown here).

one has to "normalize" observations with respect to the intensity of the Earth's magnetic field. The second effect concerns mid-latitude ULF/ELF electrostatic turbulence: since it is expected that possible seismic signals have low amplitude, the influence of parasitic signals from the spacecraft subsystems and/or other instruments must be carefully evaluated. To cope with these possible sources of errors, a sophisticated statistical data processing has been undertaken, starting first with day-side observations because of the clear morphology of natural plasma waves with intense hiss emissions easily distinguishable from whistlers [28]. A study is currently in progress to adapt the processing algorithms to night-side data where plasmaspheric emissions are much fainter and dominated by usually large and abundant whistler emissions.

The processing method uses Survey VLF spectra from ICE and is based on an automatic signal recognition algorithm which first distinguish "clean" hiss spectra from whistler dominated spectra. The algorithm provides a reduced set of "characteristic points" that allow to fully characterize the electrostatic turbulence, the ordinary and extra-ordinary EM hiss emissions (peak frequency and intensity, cut-off frequencies, etc.), the lower hybrid emissions when they occur with high enough levels and, at frequencies above $10 \mathrm{kHz}$, the VLF transmitters. An important feature of the method is to minimize the quantity of information needed to properly characterize the wave emissions in order to ease subsequent statistical studies while keeping a very accurate description of the spectra. Examples of the information provided by the automatic recognition algorithm are presented in Fig. 5.

\subsubsection{Electrostatic turbulence}

One of the mechanisms suggested to explain a pre-seismic lithosphere-ionosphere coupling (e.g. [29]) is based on the existence of a background of low amplitude atmospheric gravity waves (AGWs) close to the epicentre before the earthquake. When interacting with the ionospheric plasma AGW produce plasma irregularities which may become unstable in a drifting plasma and give rise to electrostatic turbulence. Thus the detection and characterization of faint electrostatic turbulence signals in the ULF/ELF range appears as an important objective of DEMETER. Natural EM ELF signals and parasitic interferences from various sources in the S/C subsystems and payload instruments have to be eliminated very carefully when one wants to reliably detect faint natural electrostatic emissions. A specific study has been conducted by Onishi and Berthelier [28], to distinguish true electrostatic turbulence signals from ELF spherics and whistlers signals that may have a significant amplitude down to $\sim 50 \mathrm{~Hz}$ and from parasitic signals generated by the sweeps of the ISL probe the amplitude of which depends in a complex way on the plasma density. In the following subsection we report some initial results from an on-going statistical study of electrostatic turbulence and observations related to the May 12, 2008 Sichuan earthquake.

Fig. 6 shows the power spectral density of electrostatic turbulence at $20 \mathrm{~Hz}$ plotted as function of time and geomagnetic latitude for the period August-December 2007 characterized by one of the lowest prolonged solar activity ever observed. As shown by Legrand and Simon [30,31], recurrent magnetic activity tends to be a dominant feature at low solar activity and, from the 27 day periodicity of the Dst or am indices during such periods they concluded that the recurrent magnetic activity arises from fast solar wind streams flowing from active regions on the Sun. In Fig. 6 one observes a striking correlation between the low-latitude boundary of the region of intensified electrostatic turbulence and the amplitude of the am index of magnetic activity. This can be interpreted by the penetration of auroral electric fields in the plasmasphere, with the penetration boundary moving equatorwards when the magnetic activity increases. As shown in the insert of Fig. 6 the electrostatic turbulence intensity displays a strong peak at the 27 day Sun rotation period as does the recurrent magnetic activity.

Fig. 7 represents the averaged statistical occurrence of electrostatic turbulence, in percent of the total number of observations, as a function of season, geomagnetic latitude and magnetic activity (am index). The corresponding data were acquired during 4 years, from 2005 to 2008, in a longitude sector extending over $\sim 30^{\circ}$ and centred on the Sichuan region. Two power levels measured at $20 \mathrm{~Hz}$ have been represented corresponding to 2 thresholds, respectively 0.1 and $1 \mu \mathrm{V}^{2} / \mathrm{m}^{2} / \mathrm{Hz}$. The low power signals correspond to faint emissions just above background which extend over a wide range of latitude down to $\sim 10^{\circ}$ with a clear minimum at equator, except during northern winter where the boundary is located at $\sim 20^{\circ}$ latitude. As expected, the occurrence rate is larger when magnetic activity increases. For the 3 month period encompassing 

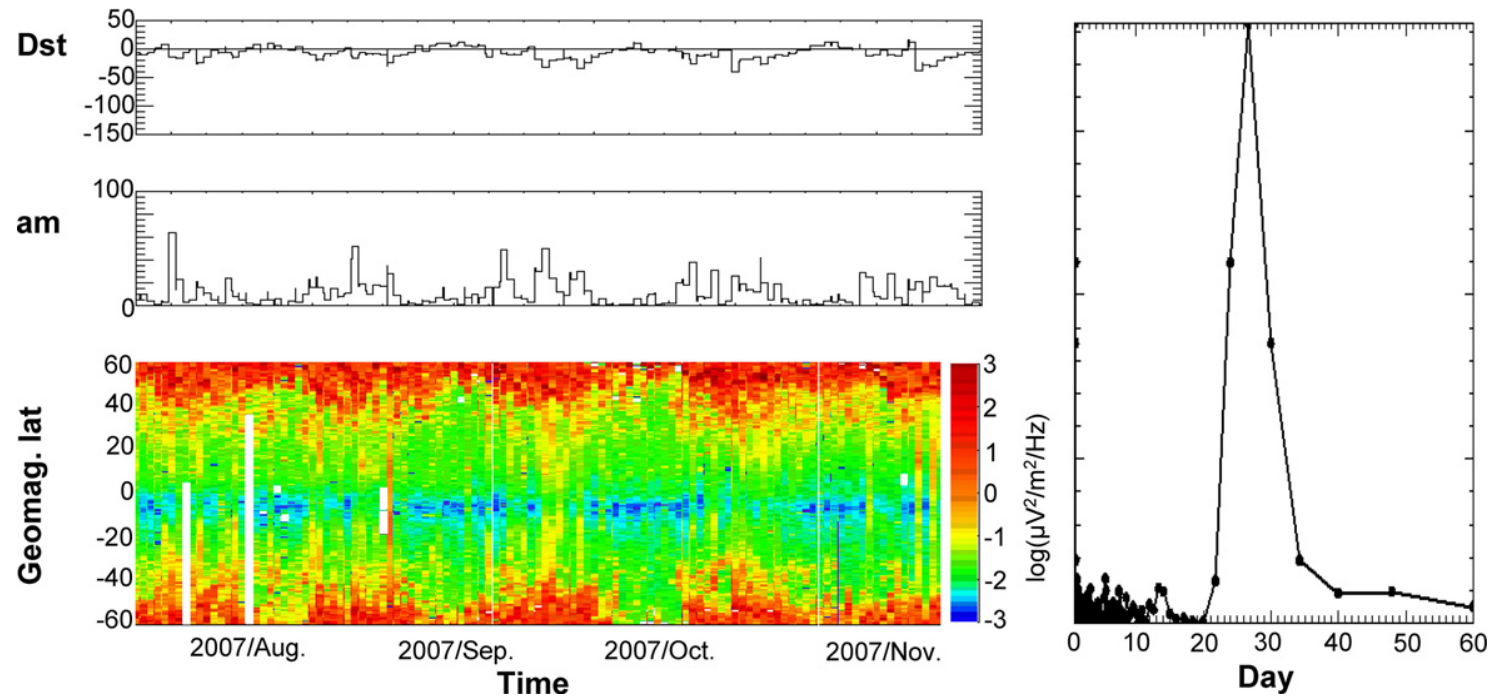

Fig. 6. Power spectral density at $20 \mathrm{~Hz}$ from August to December, 2007 with Dst and am indices. Data are not shown where whistler-type emissions are detected. The FFT analysis performed on the electrostatic turbulence spectral density shows the 27 day periodicity.

Power level $>0.1 \mu \mathrm{V}^{2} / \mathrm{m}^{2} / \mathrm{Hz}$
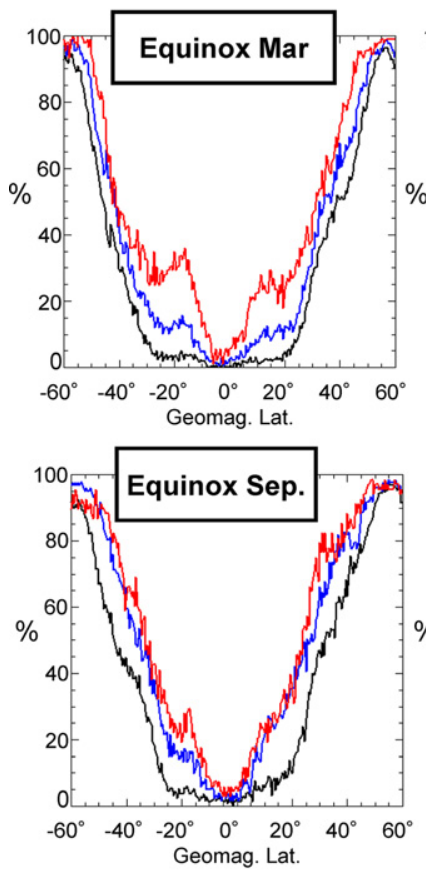
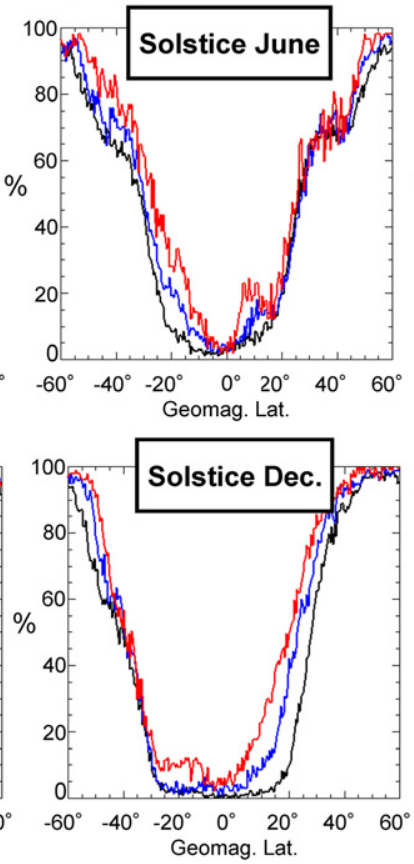

Power level $>1.0 \mu \mathrm{V}^{2} / \mathrm{m}^{2} / \mathrm{Hz}$
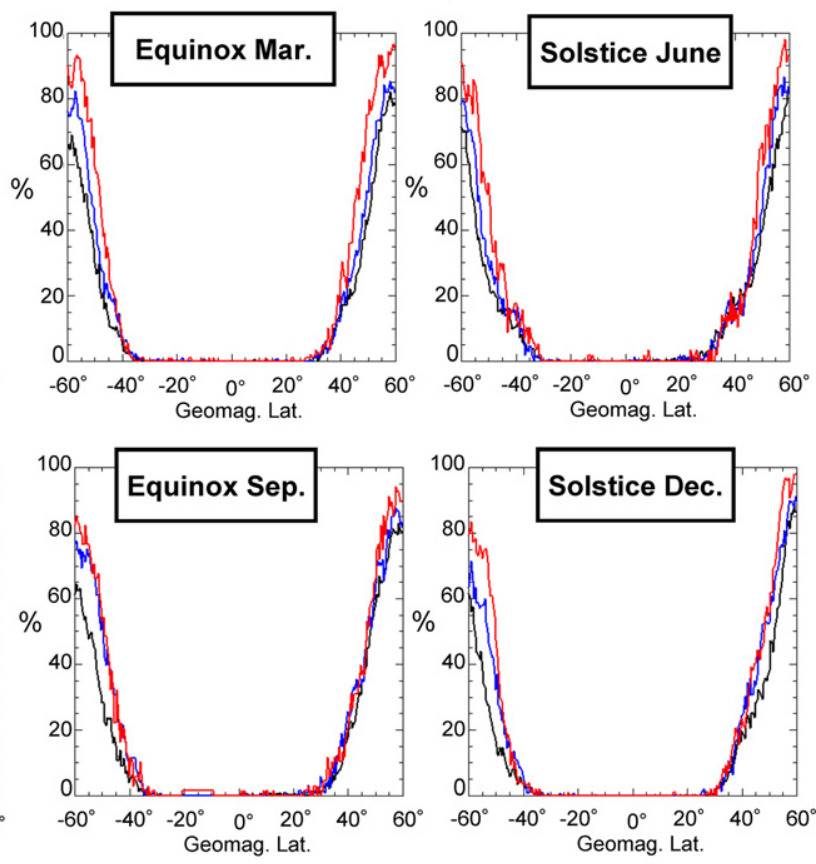

Black: $0<$ am $<10$, Blue: $10<$ am $<20$, Red: $20<$ am

Fig. 7. Occurrence probability of electrostatic turbulence in two different classes of intensity corresponding to lower threshold levels of $0.1 \mathrm{and} 1 \mu \mathrm{V}^{2} / \mathrm{m}^{2} / \mathrm{Hz}$ respectively.

the March equinox and for a large enough magnetic activity, the latitude profiles show two clear shoulders with secondary maxima in the tropical regions close to $20^{\circ}$. At June and December solstices, the latitude profiles exhibit a reduced average probability with a single less intense maximum in the winter hemisphere. Signals with a power level above $1.0 \mu \mathrm{V}^{2} / \mathrm{m}^{2} / \mathrm{Hz}$ correspond to the existence of intensified sporadic events thought to be associated with surges of auroral activity. They are observed at latitudes above $\sim 40^{\circ}$, irrespective of the level of activity but, above this low-latitude boundary, their occurrence rate increases with magnetic activity. This is in agreement with data shown in Fig. 6 where electrostatic turbulence with a power level of $1.0 \mu \mathrm{V}^{2} / \mathrm{m}^{2} / \mathrm{Hz}$ is very seldom observed below $40^{\circ}$.

The same data were used to search for a possible ionospheric anomaly related to Great Sichuan earthquake of May 12, 2008. Shown in Fig. 8 for the period 2005-2008 are the calculated power densities of the electrostatic turbulence at $20 \mathrm{~Hz}$ 


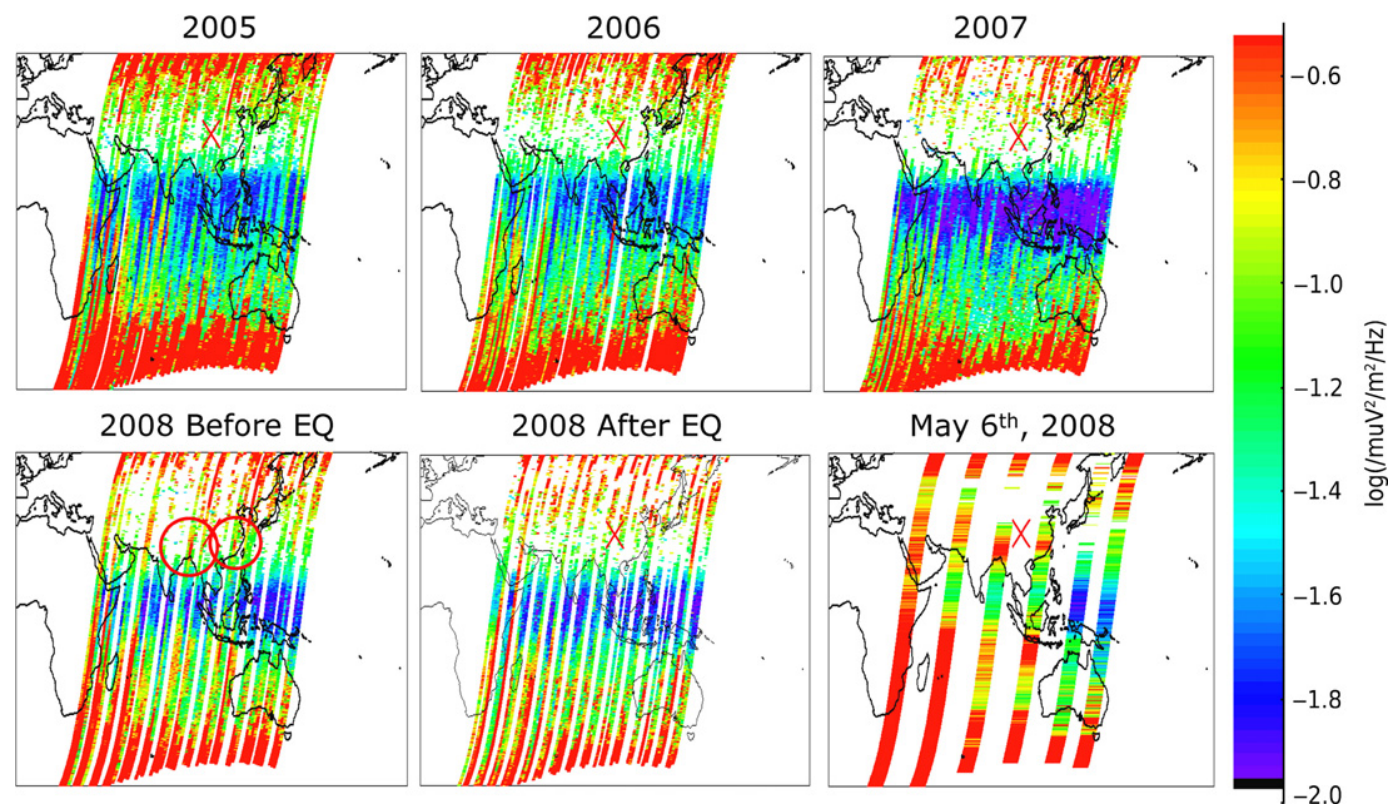

Fig. 8. $20 \mathrm{~Hz}$-power spectral density over Sichuan region between May 2nd and 22nd from year 2005 to 2008 . The epicentre of the Great Sichuan EQ on May 12th, 2008, is marked with a red cross. On May 6th, 2008, 6 days prior to the Great Sichuan EQ, 6 half-orbits span from east to west a $\sim 100^{\circ}$ longitude sector centred on the Sichuan region, the time difference between two consecutive orbits being about 100 minutes.

along orbits within $\sim 60^{\circ}$ longitude of the epicentre. Data influenced by parasitic signals have been removed and the power density is color coded in the range 0.01 to $0.3 \mu \mathrm{V}^{2} / \mathrm{m}^{2} / \mathrm{Hz}$. The epicentre is indicated by a red cross. Smooth local maxima, indicated by red circles, are observed close to the epicentre on two orbits before the earthquake. No similar gradual and localized increase of the intensity of the electrostatic turbulence was observed in the same area during the previous 3 years, nor after the earthquake. The events were detected on two consecutive orbits on May 6, 6 days prior to the earthquake. An increase of the intensity of the electrostatic turbulence is also observed along the same orbits close to the conjugate points in the southern hemisphere. It is thus tempting to relate these observations to those of Liu et al. [32] who have reported large anomalies of the F-region electron density profiles on the same day over the Sichuan region and concluded to the existence of an ionospheric disturbance of seismic origin 6 days before the EQ. However, on the first orbit, east of the epicentre, the level of electrostatic turbulence at the southern conjugate point is significantly larger than at the northern end of field lines close to the epicentre. This seems difficult to understand if the disturbance arises from a pre-seismic activity in the area of the future earthquake. A more detailed investigation is currently in progress, using complementary data, to better understand the exact nature of the observed phenomena and determine their possible association with a seismic activity preceding the Sichuan earthquake. This simple example illustrates the necessity of a careful examination of all available observations to reliably disentangle possible seismic effects from the numerous physical mechanisms that may induce significant disturbances in the ionosphere.

\section{Conclusion}

We have reviewed a few examples of the results brought by DEMETER and related to the main scientific objectives of the mission. The search for ionospheric disturbances associated with a pre-seismic activity has already provided a few observations of interest. The most significant is the decrease of the EM wave intensity in the 1 to $2 \mathrm{kHz}$ bandwidth reported by Němec et al. [26]. Disturbances can be observed prior to some earthquakes but not for all of them, which can be easily understood since the generation mechanisms are certainly related to crust composition and configuration and to the detailed characteristics of the main shock, in particular its depth. It must also be pointed out that seismic processes that may induce ionospheric disturbances are likely to occur sporadically rather than continuously. DEMETER is at a short enough distance, say less than $1500 \mathrm{~km}$, from a given epicenter only for 3 minutes per day which makes the survey of the seismic areas far from being complete. For this reason, statistical studies over a large number of quakes appear as the only way to produce meaningful results. Nevertheless, and in particular in the case of plasma measurements, a thorough check of all available observations is often necessary to ascertain that the observed phenomena cannot arise from a number of other physical mechanisms in the neutral and ionized environment of the Earth that are known to have a strong influence on the behavior and dynamics of the ionosphere. Thanks to the large and still growing data base constituted during the extended DEMETER mission, a number of studies are currently in progress that should provide new and improved results in the near future.

The nearly continuous survey of wave emissions over a wide frequency range has also lead to a large number of new observations in other domains, concerning in particular the effects of high power VLF transmitters and thunderstorm activity. 
Several studies were performed to support the preparation of the future CNES micro-satellite mission TARANIS devoted to the study of Transient Luminous Events that are triggered by discharge processes occurring between the top of thunderstorm clouds and the bottom of the ionosphere.

The DEMETER mission will come to an end in December 2010 after more than 6 years of fully successful technical and scientific operations. The DEMETER Science Mission Center (http://demeter.cnrs-orleans.fr/) will be closed one year later, at the end of 2011, and the data will be transferred to the French data centre for space plasma physics CDPP (http: //cdpp.cesr.fr/).

\section{Acknowledgements}

We want to thank the CNES teams in charge of the DEMETER project and its in-flight operations and D. Lagoutte, J.Y. Brochot and S. Berthelin for their remarkable work at the DEMETER Science Mission Centre. One of us (T.O.) benefited from a CNES funded non-permanent position during the course of the DEMETER data analysis phase.

\section{References}

[1] J. Milne, Earthquakes in connection with electric and magnetic phenomena, Trans. Seismol. Soc. Japan 15 (1890) 135.

[2] S.A. Pulinets, K.A. Boyarchuk, Ionospheric Precursors of Earthquakes, Springer, Hedelberg, New York, 2004.

[3] F. Freund, D. Sornette, Electro-magnetic earthquake bursts and critical rupture of peroxy bond networks in rocks, Tectonophysics 431 (1) (2007) 33-47.

[4] F. Freund, Stress-activated positive hole carries in rocks and the generation of pre-earthquake signals, in: M. Hayakawa (Ed.), Electromagnetic Phenomena Associated with Earthquakes, Transworld Research Network, 2009, pp. 41-96 (Ch. 3).

[5] T. Cussac, et al., The DEMETER microsatellite and ground segment, Planet. Space Sci. 54 (5) (2006) $413-427$.

[6] J.J. Berthelier, et al., ICE the electric field experiment on DEMETER, Planet. Space Sci. 54 (5) (2006) $456-471$.

[7] M. Parrot, et al., The magnetic field experiment IMSC and its data processing onboard DEMETER: scientific objectives, description and first results, Planet. Space Sci. 54 (5) (2006) 441-455.

[8] J.P. Lebreton, et al., The ISL langmuir probe experiment and its data processing onboard DEMETER: scientific objectives, description and first results, Planet. Space Sci. 54 (5) (2006) 472-486.

[9] J.J. Berthelier, et al., IAP, the thermal plasma analyzer on DEMETER, Planet. Space Sci. 54 (5) (2006) 487-501.

[10] J.A. Sauvaud, et al., High-energy electron detection onboard DEMETER: the IDP spectrometer, description and first results on the inner belt, Planet. Space Sci. 54 (5) (2006) 502-511.

[11] D. Lagoutte, et al., The DEMETER science mission centre, Planet. Space Sci. 54 (5) (2006) 428-440.

[12] D. Nunn, et al., On the nonlinear triggering of VLF emissions by power line harmonic radiation, Ann. Geophys. 17 (1999) $79-94$.

[13] J. Manninen, Power line harmonic radiation, in: J. Kultima (Ed.), Some Aspects of ELF-VLF Emissions in Geophysical Research, in: Sodankylä Geophys. Obs. Publ., vol. 98, Oula Univ. Press, Sodankylä, Finland, 2005, pp. 53-84, available at http://www.sgo.fi/Publications/SGO/thesis/ManninenJyrki.pdf.

[14] F. Němec, et al., Comparison of magnetospheric line radiation and power line harmonic radiation: a systematic survey using the DEMETER spacecraft, J. Geophys. Res. 112 (2007) A04301, doi:10.1029/2006JA012134.

[15] F. Němec, et al., Power line harmonic radiation: a systematic study using DEMETER spacecraft, Adv. Space Res. 40 (2007) $398-403$.

[16] F. Němec, et al., Power line harmonic radiation observed by satellite: properties and propagation through the ionosphere, J. Geophys. Res. 113 (2008) A08317, doi:10.1029/2008JA013184.

[17] M. Parrot, et al., Penetration of lightning MF signals to the upper ionosphere over VLF ground-based transmitters, J. Geophys. Res. 114 (2009) A12318, doi:10.1029/2009JA014598.

[18] F. Němec, et al., Survey of magnetospheric line radiation events observed by the DEMETER spacecraft, J. Geophys. Res. 114 (2009) A05203, doi:10.1029/2008JA014016.

[19] M. Parrot, et al., First in-situ observations of strong ionospheric perturbations generated by a powerful VLF ground-based transmitter, Geophys. Res. Lett. 34 (2007) L11111, doi:10.1029/2007GL029368.

[20] J.-A. Sauvaud, et al., Radiation belt electron precipitation due to VLF transmitters: Satellite observations, Geophys. Res. Lett. 35 (2008) L09101, doi:10.1029/2008GL033194.

[21] M. Parrot, et al., Examples of unusual ionospheric observations made by the DEMETER satellite over seismic regions, Phys. Chem. Earth 31 (2006) 486-495, doi:10.1016/j.pce.2006.02.011.

[22] M. Parrot, Anomalous seismic phenomena: View from space, in: M. Hayakawa (Ed.), Electromagnetic Phenomena Associated with Earthquakes, Transworld Research Network, 2009, pp. 205-233.

[23] M. Akhoondzadeh, M. Parrot, M.R. Saradjian, Electron and ion density variations before strong earthquakes (M > 6.0) using DEMETER and GPS data, Nat. Hazards Earth Syst. Sci. 10 (2010) 7-18.

[24] H. Risbeth, M. Mendillo, Patterns of F2-layer variability, J. Atm. Solar Terr. Phys. 63 (2001) 1661-1680.

[25] R. Marchand, J.J. Berthelier, Simple model for post seismic ionospheric disturbances above an earthquake epicentre and along connecting magnetic field lines, Nat. Hazards Earth Syst. Sci. 8 (2008) 1341-1347.

[26] F. Němec, et al., Spacecraft observations of electromagnetic perturbations connected with seismic activity, Geophys. Res. Lett. 35 (2008) L05109, doi:10.1029/2007GL032517.

[27] R.G. Harrison, K.L. Aplin, M.J. Rycroft, Atmospheric electricity coupling between earthquake regions and the ionosphere, J. Atm. Solar Terr. Phys. 72 (5-6) (2010) 376-381.

[28] T. Onishi, J.J. Berthelier, Synthetic description of VLF electric field spectra from the ICE experiment on DEMETER, automatic recognition and characterization of natural and man-made emissions, in: Notes du Pôle de Planétologie, Institut Pierre-Simon Laplace, June 2010, http://www.ipsl.fr/fr/ Documentation/Les-publications-de-l-IPSL/.

[29] O. Molchanov, et al., Global diagnostics of the ionospheric perturbations related to the seismic activity using the VLF radio signals collected on the DEMETER satellite, Nat. Hazards Earth Syst. Sci. 6 (2006) 745-753.

[30] J.P. Legrand, P.A. Simon, Ten cycles of solar and geomagnetic activity, Solar Phys. 70 (1981) 173-195.

[31] J.P. Legrand, P.A. Simon, A two-component solar cycle, Solar Phys. 131 (1991) 187-209.

[32] J.Y. Liu, et al., Seismoionospheric GPS total electron content anomalies observed before the 12 May 2008 Mw7.9 Wenchuan earthquake, J. Geophys. Res. 114 (2009) A04320, doi:10.1029/2008JA013698. 